\title{
Costs of Taxation and Benefits of Public Goods with Multiple Taxes and Goods
}

\author{
James E. Anderson \\ Will Martin \\ Boston College \\ World Bank
}

30 January 2010

\begin{abstract}
The fact that raising taxes can increase taxed labor supply through income effects is frequently used to justify greater public good provision than indicated by traditional, compensated analyses. We develop a model including multiple public goods and taxes and derive consistent measures of the marginal benefit of public goods and their marginal social cost inclusive of tax distortions using both compensated and uncompensated measures of the Marginal Cost of Funds (MCF). Our analysis confirms that the desirability of tax financed public projects is independent of whether compensated or uncompensated methods are used. The main innovation shows that the costs or benefits of providing particular public goods should be adjusted by a simple, benefit multiplier not previously seen in the literature if an uncompensated MCF is used.
\end{abstract}

JEL Code: D61, F11, H21, H43.

Keywords: fiscal policy; second best; public goods; distortions; costs of taxation, marginal cost of funds; marginal excess burden, thought experiment.

Correspondence to: Will Martin, Development Research Group, World Bank, MSN3303, 1818 H St NW, Washington DC 20433. Tel: 202473 3853; Fax 202522 1159; wmartin1@worldbank.org or Jim Anderson, Boston College, james.anderson.1@bc.edu. 


\section{Costs of Taxation and Benefits of Public Goods with Multiple Taxes and Goods}

The welfare benefits of providing public goods and the welfare costs of taxation to pay for them are among the most thoroughly analyzed subjects in public economics. The reason readers of this journal should read our paper is that—despite this vast volume of work - an extremely consequential confusion between two methods of application besets applied work. The fact that raising taxes can increase taxed labor supply through income effects is frequently used to justify greater public good provision than indicated by traditional, compensated analysis. We develop a model including multiple public goods and taxes and derive consistent measures of the marginal benefit of public goods and their marginal social cost inclusive of tax distortions using both compensated and uncompensated measures of the Marginal Cost of Funds (MCF). Our analysis confirms that the desirability of tax financed public projects is independent of whether compensated or uncompensated methods are used. Our main innovation is to show thatif an uncompensated MCF is used - the welfare benefits of providing public goods must be adjusted by a simple factor not previously seen in the literature.

Stiglitz and Dasgupta (1971) and Atkinson and Stern (1974) changed the field by identifying a previously-ignored income effect as a potentially important influence on the costs of taxes bearing on labor that are used to provide public goods. The intuition is very simple. If leisure is a normal good, raising taxes raises reduces disposable incomes and hence the demand for leisure, increasing the supply of taxed labor (Atkinson and Stern 1974, p123). Triest (1990, p558), Ballard and Fullerton (1992) and Dahlby (1998; 2008, p46) subsequently identified a consensus in the literature that estimates of the marginal 
cost of funds (MCF) raised for the provision of public goods should take these income effects of taxation into account.

Many studies have attributed important policy implications to this methodological change from traditional approaches to the marginal cost of funds (eg Browning 1976, 1987) based purely on compensated responses. Atkinson and Stern (1974, p127), Auerbach (1985, p112) and Ballard and Fullerton (1992, p122) suggest that the income effects associated with raising taxes reduce the social costs of taxes on labor and hence expand the range of public goods optimally provided by governments. This consensus stands in striking contrast to Hatta's (1977) famous conclusion that the sign of the welfare effects of a price policy change does not depend on income effects.

It appears that the policy impact of a change to the uncompensated MCF can be very large in real-world cases. Fullerton's (1991) analysis suggested that the marginal efficiency cost of a dollar of US government revenue from taxes that bear on labor was only a quarter as large when these income effects were included ${ }^{1}$. Although Feldstein (1999) includes a broader range of substitution effects, the inclusion of income effects still halves the apparent marginal welfare cost of taxation in his analysis.

As well as appearing to have major policy implications, including the income effects of taxation without those associated with public good provision considerably complicates policy analysis. Ballard (1990), Mayshar (1990), Creedy (2000) Dahlby (2008) and others have argued that the approach used to calculate the costs taxes used for public goods should differ from that used for evaluating balanced-budget changes in tax rates. Under this view, at least two MCF measures are seen to be needed, depending upon

\footnotetext{
${ }^{1}$ For consistent and widely-adopted elasticity values, Fullerton (1991) estimated the Marginal Excess Burden (MEB) excluding these income effects - which he defined as (MCF-1) — of US labor taxes as 0.25 and the MEB including these income effects as 0.07 .
} 
the type of "thought experiment" being conducted. One such measure, including the income effects of taxation, is to be used for balanced-budget experiments in which taxes are raised for use in "exhaustive" government spending; the other, with income effects excluded, for "differential-incidence" experiments such as changes in the taxes used to raise a particular amount of government revenue (Ballard 1990).

It seems clear that the model used to make a full assessment of the implications of tax and spending changes must represent the income effects of both tax measures and public good provision. A surprising feature of the way these income effects have been included in much of the literature is its partial nature. The tax revenue effects resulting from the real income changes due to provision of public goods have not been explicitly treated, except in a few studies such as Wildasin (1984), Browning, Gronberg and Liu (2000) and Slemrod and Yitzhaki (2001). The inclusion of these effects is particularly important in the increasing number of applied studies modeling the impacts of government expenditures on multiple goods (Bourguignon, Diaz-Bonilla and Lofgren 2008). Even in conceptual studies, we find that including income effects in a more comprehensive way substantially simplifies the analysis, allowing all income effects to be collected in a multiplier independent of the taxes being changed or public goods being provided, along the lines of the Hatta $(1977, \mathrm{p} 4)$ decomposition.

Our collection of mutually consistent expressions for the marginal cost of funds and the marginal benefit of public goods under compensated and uncompensated approaches provide a crib sheet for applied public policy modeling. These expressions can be used to diagnose why particular models give their particular results, enlightening sensitivity analysis. Equally important, they allow policy analysis to be decentralized. 
Once a model has been developed which provides the marginal cost of funds for a particular set of tax reforms identified by the those responsible for raising revenues, those responsible for decisions on particular public goods can assess the net benefits of providing those goods without needing access to a complete model of the economy. While many important studies in this literature, such as Wildasin (1984) and Browning, Gronberg and Liu (2000) have focused on models with a single tax and a single public good, we think it useful to follow Wildasin's (1984) recommendation and develop a model that allows for multiple taxes and multiple public goods. Real-world governments engaged in planning their fiscal policies face many decisions about which tax bases to tap, at which rates, and it is important to have a conceptual framework that allows for effects of changes in different tax instruments (see, for example, Auriol and Warlters 2006), and for the evaluation of multiple publicly-provided goods, whose impacts on producer incomes and consumer welfare are the subject of the burgeoning literature on impact evaluation (see, for example, Ravallion 2008; Khandker, Koolwal and Samad 2010)

Browning, Gronberg and Liu (2001) conclude that either the compensated or the uncompensated $\mathrm{MCF}$ can be used for welfare evaluation, as long as they are compared with the right measures of the marginal benefit of public goods. We agree with their conclusion, but are concerned that their index-number formulation provides little insight into the reasons for the adjustments to the value of public goods. In this paper, we derive measures of the benefits (or costs) of public goods that provide more intuition into the reasons for the differences between the measures, and a more accessible guide for practical policy analysis. To foreshadow one of our key results, we show that use of an 
uncompensated measure of the MCF requires adjustment to the benefits of providing public goods by a scalar multiplier that depends upon the income effects on all taxed private goods.

In section I, we provide a simple model incorporating all relevant income effects that can be used to evaluate the benefits of public goods and the costs of taxation. Then, in Section II, we use it to estimate the implications of providing public goods and raising funds to pay for them. In Section III, we examine the implications of using compensated and uncompensated measures of the cost of taxation when evaluating provision of public goods and show the adjustments to the value of public goods needed when using the uncompensated approach. Section IV concludes.

\section{The Model}

For our analysis, we need to represent government production; the behavior of consumers and producers, including the value to them of public goods; and the budget constraints of the government and the private sector. As well as allowing for conventional consumer demand and labor supply responses, the framework used must allow for the broader responses of taxable income to changes in taxes emphasized by authors such as Feldstein (1995, 1999) and Gruber and Saez (2002). It must also allow for choices between investments in many different public goods, and many different possible taxes. To meet these needs, we develop a model of a competitive single-household ${ }^{2}$ economy, incorporating a cost function for government provision of public goods; an expenditure

\footnotetext{
${ }^{2}$ Inclusion of multiple households and different distributional weights is feasible (see Dahlby 2008), but would complicate the analysis without providing additional insights into the issues we consider. The valuation of the overall "household" for any public good includes, following Samuelson (1954), the sum of the marginal rates of substitution (MRS) of the individual people represented by this household, relative to a numeraire private good. In this analysis, we consider, in addition, the value of public goods in production.
} 
function to characterize behavior of the good-consuming and factor-supplying household; a profit function to represent production activities; and budget constraints for the private sector and government.

For simplicity and for consistency with most of the literature, we assume that market prices of goods and factors are constant either because the production structure is linear or because of international trade in a small economy ${ }^{3}$. Some private goods and services are not subject to taxes and their price is the numeraire. Market prices of private goods are shown by $\mathrm{p}$. The vector $\mathrm{q}$ refers to the prices of private goods and services faced by the household, and the vector of taxes is given by (q-p). In this analysis, we consider only linear taxes ${ }^{4}$ on privately consumed or supplied goods and factors, although generalizations to taxes on trade (Anderson and Martin 1996) or production are straightforward.

Costs of providing public goods ${ }^{5}$ are represented by a government cost function $\mathrm{c}(\mathrm{G}, \mathrm{p}, \lambda)$ which shows the direct costs paid by the government for the inputs of private goods and services it uses to produce its exogenously-supplied vector of public goods ${ }^{6}, \mathrm{G}$. This cost is determined by market prices, $p$, and a vector of efficiency parameters, $\lambda$, as well as the government's supply of public goods, G. We assume that the government cost function is a well-behaved multi-input, multi-output cost function. This specification

\footnotetext{
${ }^{3}$ As shown by Komiya (1967) and Deardorff and Courant (1990), market prices of factors may be determined by border prices of commodities in a small, open economy even when some goods are nontraded, and the production technology allows for substitution between factors. Neary (1995) provides a framework for extending the type of analysis reported in this paper to the case where market prices change.

${ }^{4}$ Our linear specification is much more general than it might appear. With the addition of lump sum transfers, it could capture the effects of marginal changes in progressive taxes (Ballard and Fullerton 1992). We do not include these transfers since they are not used in our experiments.

${ }^{5}$ Our analysis extends beyond pure public goods to any good which is made available without charge in a quantity determined by the government, even if that good is rival and/or potentially excludable in consumption.

${ }^{6}$ Like Liu (2004), we think it desirable to use a specification in which governments produce their outputs using private goods and factors, rather than transforming them directly from consumption goods.
} 
implies that governments seek to minimize the costs of producing their chosen vector of outputs. If costs are higher or input demands less price-responsive than they would be in a competitive market environment, this can be represented through the $\lambda$ parameters, and/or through lower price response parameters, $c_{\mathrm{pp}}$. Standard minimum-value function properties imply that the first derivative of $\mathrm{c}$ with respect to $\mathrm{G}, \mathrm{c}_{\mathrm{G}}$, is a vector of the marginal costs of providing public goods, taking into account the fact that provision of a new public good may affect the costs of providing existing public goods - as in the case where building a road to a lighthouse lowers the cost of running the lighthouse. In Samuelson's (1954) terminology, $\mathrm{c}_{\mathrm{G}}$ corresponds to the marginal rate of transformation (MRT) between public goods and a private numeraire good.

Household behavior is represented by a constrained expenditure function $\mathrm{e}(\mathrm{q}, \mathrm{G}, \mathrm{u})$ which gives the minimum net expenditure on private goods necessary to maintain the utility level of a representative household given a vector of public goods, G. The derivative of e with respect to q gives the vector of goods demanded by households, while goods and services supplied by households, such as labor, are represented by negative elements of $e_{q}$ and associated with negative elements of (q-p). The second derivatives of $\mathrm{e}$ with respect to $\mathrm{q}, \mathrm{e}_{\mathrm{qq}}$, are the responses of consumer demands and household factor supplies to changes in q, including the extensive-margin or market participation responses highlighted by Kleven and Kreiner (2006). G appears in the expenditure function because public goods affect welfare directly through the cost—in terms of private goods — of achieving a given level of utility. For example, government provision of police services may reduce the private expenditures on security needed to achieve the same level of utility. 
Producer behavior must be included in the model because government activities are frequently designed to increase productivity in the production sector. It is represented by a constrained gross domestic product (GDP) function, $g(p, G)$ which shows the net profits obtained from production activities after purchasing supplied factors and intermediate inputs at market prices, p. G appears in the GDP function because an increase in G may increase profits from production, even at constant producer prices, as when government-provided roads lower the costs of transporting intermediate goods. The vector q does not appear because we focus here on taxes levied on households, such as excise taxes and income taxes.

Private sector behavior overall is represented by a net expenditure function, E, defined as the difference between the representative consumer's constrained expenditure? function, $\mathrm{e}(\mathrm{q}, \mathrm{G}, \mathrm{u})$, and the constrained gross domestic product function, $\mathrm{g}(\mathrm{p}, \mathrm{G})$.

Increases in elements of $\mathrm{G}$ which are valued by the household and/or producers will lower the private cost of achieving any given level of utility. These valuations are given by the vector $\mathrm{E}_{\mathrm{G}}$ which is negative for products valued by the private sector, and equal to minus the virtual price vector, $\pi$, or the marginal willingness to pay of the private sector for the goods. The value of $\pi$ depends on the value placed by the private sector on changes in public good supply, and on any impacts of their provision on the private sector's valuation of existing public goods - as in the case where an additional section of road raises the value of existing roads by providing easier access to them.

\footnotetext{
${ }^{7}$ The expenditure function may represent the supply of labor from the representative household using negative demands for supplied commodities.

${ }^{8}$ Note that $\pi$ incorporates Samuelson's sum of the valuations of public goods by individual consumers, $\mathrm{e}_{\mathrm{G}}$, and their valuation by the production sector, $\mathrm{g}_{\mathrm{G}}$.
} 
Budget constraints: The government budget constraint and the private-sector budget constraint are defined as:

$$
\begin{array}{lll}
\mathrm{c}(\mathrm{G}, \mathrm{p}, \lambda)-[\mathrm{q}-\mathrm{p}] \mathrm{e}_{\mathrm{q}}(\mathrm{q}, \mathrm{G}, \mathrm{u}) & =\beta & \text { government budget constraint } \\
\mathrm{E}(\mathrm{q}, \mathrm{p}, \mathrm{G}, \mathrm{u}) & =\alpha & \text { private budget constraint } .
\end{array}
$$

The government budget constraint in (1) specifies that the government deficit, or spending on its input purchases less its revenue from taxes on consumption or factor supply, is equal to an exogenous transfer from the rest of the world, $\beta$. The private-sector budget constraint, (2), sets net expenditure by the private sector equal to an exogenous transfer to the private sector from the rest of the world, $\alpha$. In all of our analyses, simultaneous solution of the government and private budget constraints ensures that the national budget constraint is satisfied.

While we do not need these extensions, it is clear that the model could readily be generalized to include user charges on government-provided goods where these are feasible; lump-sum transfers from the government to the household; taxes on government agencies' purchases of inputs; and taxes on trade or on business inputs and outputs.

\section{Analyzing Provision of Public Goods}

We analyze a parametric change in $\mathrm{G}$, financed by an endogenous change in taxes, resulting in a change in the prices faced by households, dq. Totally differentiating (1) and (2) with respect to G, $q$ and $u$ we obtain:

$$
\begin{aligned}
& {\left[\mathrm{c}_{\mathrm{G}}{ }^{\prime}-(\mathrm{q}-\mathrm{p})^{\prime} \mathrm{e}_{\mathrm{qG}}\right] \mathrm{dG}=\left[\mathrm{e}_{\mathrm{q}}{ }^{\prime}+(\mathrm{q}-\mathrm{p})^{\prime} \mathrm{e}_{\mathrm{qq}}\right] \mathrm{dq}+(\mathrm{q}-\mathrm{p})^{\prime} \mathrm{e}_{\mathrm{qu}} \mathrm{du}} \\
& \mathrm{E}_{\mathrm{G}}{ }^{\prime} \mathrm{dG}+\mathrm{e}_{\mathrm{q}} \mathrm{dq}^{+}+\mathrm{e}_{\mathrm{u}} \mathrm{du}=0 .
\end{aligned}
$$


The term pre-multiplying $\mathrm{dG}$ in (3) combines the direct cost of government outputs, $\mathrm{c}_{\mathrm{G}}$, with the impact of the change in $\mathrm{G}$ on government tax revenues through complementarity/substitutability relationships, $(\mathrm{q}-\mathrm{p})^{\prime} \mathrm{e}_{\mathrm{qG}}$, originally identified by Diamond and Mirrlees (1971). This coefficient on $\mathrm{dG}$ is the full fiscal cost of the public outputthe direct budget cost less the indirect, compensated implications of changes in $\mathrm{G}$ for tax revenues.

To maintain fiscal balance when $G$ increases, taxes must be raised through a change in $\mathrm{q}$, dq, sufficient to pay the full fiscal cost, taking into account the change in the level of the taxed activity resulting from the substitution effects of tax rate changes and public good supply, and the income effects of all of the changes involved. The term in square brackets on the right-hand side of (3) decomposes the equilibrating tax revenue change into two key components. The $\mathrm{e}_{\mathrm{q}} \mathrm{dq}$ term is the impact of the tax changes on tax revenues at initial quantities. The $(\mathrm{q}-\mathrm{p})^{\prime} \mathrm{e}_{\mathrm{qq}}$ term is the tax revenue loss and the marginal dead weight loss resulting from the household's compensated responses as prices change.

When seeking fiscal balance, governments frequently raise tax rates on different goods by different amounts, and may even lower some tax rates. Such tax packages can be represented by a diagonal matrix, $\Psi$, of weights on different price variables - where a unitary weight means full inclusion of a good in the tax reform package, and zero implies its exclusion". Given a $\Psi$ matrix and a chosen price base, ${ }^{10}$ a vector of price changes may

\footnotetext{
${ }^{9}$ Packages with a weight on only one tax can be used to assess the MCF for that tax. Combinations of weights above, and below unity might be used to increase or decrease the importance of particular taxes relative to others in the initial tax mix. The weights can also be adjusted to optimize the tax mix and minimize the MCF for a particular set of taxes.

${ }^{10}$ An intuitively-appealing tax package is one which expresses changes in tax rates relative to market prices, $p$, of taxable goods. To allow tax changes to be expressed in the widely understood format of percentage point changes in the tax rate, units might be chosen so that market prices are initially 100. Alternatively, a tax package might be defined in terms of changes in the household prices of taxable goods,
} 
be defined as dq $=\delta . \mathrm{d} \phi$ where $\delta$ is the product of $\Psi$ and the chosen base price vector, and $\mathrm{d} \phi$ is a scalar used to find the overall size of the change in tax rates needed to achieve fiscal balance. For a tax change specified relative to market prices, $\delta=\Psi$.p. As noted by Sandmo (1998, p378), whenever taxes are non-optimal, the choice of prices to be adjusted, and the relative magnitudes of the price changes to be imposed, may have important impacts—-for example, some tax reforms, such as those involving reductions in high tax rates or increases in low tax rates, may yield a compensated MCF less than unity ${ }^{11}$.

For any specified tax package, we can solve equation (3) for the scalar $\mathrm{d} \phi$ needed to maintain fiscal balance:

$$
\left.\mathrm{d} \phi=1 /\left[\mathrm{e}_{\mathrm{q}}{ }_{\mathrm{q}} \delta+(\mathrm{q}-\mathrm{p})\right)_{\mathrm{qq}} \delta\right] \cdot\left[\left\{\mathrm{c}_{\mathrm{G}}{ }^{\prime}-(\mathrm{q}-\mathrm{p})^{\prime} \mathrm{e}_{\mathrm{qG}}\right\} \mathrm{dG}-(\mathrm{q}-\mathrm{p})^{\prime} \mathrm{e}_{\mathrm{qu}} \mathrm{du}\right]
$$

The term dq in (4) may be replaced by $\delta . d \phi$ with $d \phi$ obtained using (5). Then, using $\pi$ for the virtual price of public goods ${ }^{12}, E_{G}$, we obtain two key welfare evaluation formulae for fiscal policy:

$\mathrm{q},-$ a potentially attractive approach if the initial tax mix is close to optimal. A tax package might also be defined in terms of its impact on initially-applied tax rates, as in Feldstein (1999, p678).

${ }^{11}$ As is emphasized by Drèze and Stern $(1985, \mathrm{p} 919)$, there is an element of arbitrariness in specifying how revenue impacts will be dealt with, and the combination of a bad project and a good tax reform could result in acceptance of a project that has lower returns than one evaluated against a higher MCF. A pragmatic solution, consistent with the widespread practice of calculating generalized MCFs for each economy (see Devarajan, Squire and Suthiwart-Narueput 1997), might be to specify a feasible and desirable marginal tax mix for revenue expansion (or reduction), such as might be used by a government putting together an overall budget, and to use this same MCF in the evaluation of all spending alternatives.

${ }^{12}$ Providing rigorous estimates of $\pi$ is the focus of the burgeoning literature on impact evaluation, and (6) allows the resulting estimates to be put into the context needed for decisions about the provision of these goods. Endogenous determination of $\pi$ for changing levels of government provision seems a desirable and logical approach to specifying computable models for evaluation of government expenditure programs, although few applied modeling efforts appear to have done this to date. 


$$
\left(1-\operatorname{MCF}(q-p){ }^{\prime} \chi_{\mathrm{I}}\right) \cdot \mathrm{e}_{\mathrm{u}} \mathrm{du}=\left[\pi^{\prime}-\operatorname{MCF}\left\{\mathrm{c}_{\mathrm{G}}{ }^{\prime}-(\mathrm{q}-\mathrm{p})^{\prime} \mathrm{e}_{\mathrm{qG}}\right\}\right] \mathrm{dG}
$$

and

$$
\mathrm{e}_{\mathrm{u}} \mathrm{du}=\mathrm{FM} \cdot\left[\pi^{\prime}-\mathrm{MCF}\left\{\mathrm{c}_{\mathrm{G}}{ }^{\prime}-(\mathrm{q}-\mathrm{p})^{\prime} \mathrm{e}_{\mathrm{qG}}\right\}\right] \mathrm{dG} .
$$

The right hand side of equation (6) is a compensation measure: the amount that must be transferred to or from the private sector to maintain utility at its initial level (so du=0). Equation (7) solves equation (6) for the money metric utility change $e_{u} d u$. In both equations MCF is the compensated Marginal Cost of Funds, explained below, and $\chi_{\mathrm{I}}$ is a vector of income effects, $\mathrm{e}_{\mathrm{qu}} / \mathrm{e}_{\mathrm{u}}$. On the right hand side of equation (7) the Fiscal Multiplier (FM) term, $\mathrm{FM} \equiv 1 /\left[1-\operatorname{MCF}(\mathrm{q}-\mathrm{p}) \chi_{\mathrm{I}}\right]$, is the welfare effect of a one dollar transfer from the rest of the world to the private sector, explained further below.

The expression in curly brackets is the direct cost of the good to the government adjusted by the compensated impact of its provision on tax revenues - the fiscal cost of the good identified above. The term in square brackets on the right hand side of (6) and (7) is a net impact of the change in $\mathrm{G}$ - the difference between its virtual price, $\pi$, and the product of the MCF and the fiscal cost of the public good.

As long as the FM term is assuredly positive (to be considered further below), policy choices can be based solely on the term in square brackets in equation (6), which weighs the benefits of the project to the household against the fiscal costs multiplied by the MCF. Our MCF term is defined as

$$
\mathrm{MCF} \equiv \mathrm{e}_{\mathrm{q}}{ }^{\prime} \delta /\left[\mathrm{e}_{\mathrm{q}}{ }^{\prime} \delta+(\mathrm{q}-\mathrm{p})^{\prime} \mathrm{e}_{\mathrm{qq}} \delta\right] .
$$

As is shown in the Appendix, this MCF is the compensation to the private sector needed to maintain the initial utility level when the government reduces its transfer from the rest 
of the world by $d \beta$ and meets its budget constraint by raising taxes. ${ }^{13}$ Thus, the MCF maps income in the hands of government (the social income of Little and Mirrlees (1974)) into income in the hands of the private sector ${ }^{14}$. This feature explains the attractiveness of the compensated approach to the earlier and theoretically oriented literature. Because the subsequent literature has often mixed income effects with compensated terms, it is useful to further emphasize the advantages of the compensated approach in reviewing some of that literature.

Like Schöb (1994) and Slemrod and Yitzhaki (2001), but in contrast with Snow and Warren (1996), we exclude the effects of public good provision on taxed private goods from the MCF and the related marginal welfare cost of taxation, which is MCF-1 using our compensated welfare measure. The compensated welfare effects resulting from changes in public-good provision, $(\mathrm{q}-\mathrm{p})^{\prime} \mathrm{e}_{\mathrm{qG}} \cdot \mathrm{dG}$, can usefully be thought of as part of the fiscal cost of providing particular public goods (as in equations (6) and (7)), and dealt

\footnotetext{
${ }^{13}$ This MCF term is a compensated version of the marginal efficiency cost of funds (MECF) defined by Slemrod and Yitzhaki (2001, p192). For a single-tax economy, it corresponds to the familiar compensated MCF of Mayshar (1991, p1329). Its numerator is the cost to taxpayers from a marginal change in the uniform tax surcharge, $\phi$. Its denominator is the increase in revenue achieved with the (compensated) household and government agencies free to respond to the incentives created by the tax changes. As shown in the Appendix, it shows the amount of compensation to the private sector required when the government raises an additional dollar in revenue. Because the numerator of the MCF will generally be larger than the denominator, the MCF will normally be greater than one. Note that the columns of $\mathrm{e}_{\mathrm{qq}}$ relevant to the value of the MCF are only those that correspond to a non-zero element in the vector $\delta$. This contrasts with FM, which necessarily involves all initial taxes on products with non-zero income effects.

Intuitively, the MCF measures the inefficiency of tax policy, as it generally costs more than a dollar of private income to raise fiscal revenues by one dollar. An important special case is the MCF of a tax on goods supplied or demanded by the household with zero compensated price effects relative to any price. In this case, the MCF is unity since, by symmetry, the relevant columns of $\mathrm{e}_{\mathrm{qq}}$ contain only zero elements. This intuitive property is not necessarily shared by uncompensated measures, where income effects from changes in lump-sum taxes will influence excess demands for taxed private goods whenever there are initially-taxed goods with non-zero income effects.

${ }^{14}$ In the cost-benefit literature (see, for example, Squire 1989, p1104), government outputs are typically sold to the private sector at their marginal value, allowing costs and benefits to be presented either in terms of income in the hands of government or the hands of the private sector. In our application, the costs are borne by government and the marginal benefits, $\pi$, accrue to the private sector, making conversion necessary.
} 
with separately from the costs of raising revenues. This allows the MCF to be estimated independently from decisions about the type of public goods to be supplied, and overcomes the serious obstacle to progress in obtaining better measures of the MCF identified by Snow and Warren (1996, p303) — the perceived need to include estimates of the impact of government spending on taxed activities in the MCF.

Equation (6) has an extremely simple, powerful interpretation. Whether a change in government outputs is welfare-improving depends on whether the direct valuation of the change by agents, $\pi^{\prime} \mathrm{dG}$ (or $\Sigma$ MRS.dG in the notation of Ballard and Fullerton (1992, p118), plus $\mathrm{g}_{\mathrm{G}}$ ) exceeds the compensated MCF times the fiscal costs (direct plus indirect, or the MRT plus induced, compensated, tax revenue effects) of the good. This is a key result, and provides a very simple guide to fiscal policy decisions for pure public goods. It is, in effect, a reaffirmation of the Pigou $(1947$, p34) doctrine, which has been interpreted (see Atkinson and Stern 1974; Auerbach 1985) as basing the marginal cost of funds on compensated demand responses. As we will see, this result arises because we have gathered all of the income effects on the left hand side of equation (6), rather than treating the income effects due to tax changes separately from those due to provision of public goods. The fact that all of the income effects are collected in the FM term means that, as in Hatta (1977), we can infer whether a policy change increases or decreases welfare without reference to income effects, save in the pathological case of a negative FM. That these income effects are irrelevant is a matter of mathematical logic evident from equation (7) and not, as is commonly asserted, an empirical question.

Equation (6) also reveals the fundamental problem with the widely-cited (see $\mathrm{Ng}$ 2000) conclusion of Kaplow $(1996,2004)$ that the MCF of funds used for public good 
provision should be unity. While Kaplow includes both the spending effects arising from provision of public goods and those resulting from raising taxes to pay for them, he ignores the substitution effects inherent in the MCF when concluding that the supply of labor is unaffected (p514) when taxes are raised by exactly enough to eliminate the welfare benefits arising from provision of the good. While such a compensating change in taxes can exactly offset the income effects of public-good provision, it cannot also be expected to offset the substitution effects of the tax change on the quantities of the taxed goods supplied/demanded.

Finally, we consider in more detail the FM term needed for conversion to money metric utility in going from equation (6) to equation (7) and more generally in relating compensated to uncompensated methods of evaluation. The Fiscal Multiplier measures the impact of a change in the transfer from the rest of the world to the private sector, $d \alpha$, on a money-metric measure of household welfare, as shown in the Appendix. The size of the FM term depends upon (q-p)' $\chi_{I}$ and hence upon all initial tax rates on goods whose demand or supply is affected by changes in income.

The FM is not generally unity in distorted economies because a transfer of $\$ 1$ to the private sector changes spending and thus affects tax revenues whenever any tax is levied on an income-responsive good. If the additional income in the hands of the private sector is spent on normal goods subject to positive taxes, there will be a second-round benefit from reductions in distorting taxes and FM will be greater than one. If, by contrast, the additional income increases consumption of untaxed goods, such as leisure, and hence reduces the supply of taxed goods such as labor, FM may be less than one. If these negative income effects were sufficiently strong, FM could conceivably be negative 
in sign. This seems a curiosum, since it implies a situation where the welfare of the private sector is reduced by receiving unrequited, unrestricted transfers from abroad ${ }^{15}$. But, if it occurs, this problem is real, and affects all valid measures of $e_{u} d u$, not just those that make clear its source by consolidating income terms into a coefficient like FM.

\section{Compensated vs. Uncompensated Evaluation Methods}

An uncompensated measure of the marginal cost of funds can also be obtained from equations (3) and (4). Substituting for $\mathrm{e}_{\mathrm{u}} \mathrm{du}$ from equation (4) into equation (3) ensures that the resulting equation satisfies both the government and private sector budget constraints, and hence the national income-expenditure constraint, and yields an expression:

$$
\left[\mathrm{c}_{\mathrm{G}}^{\prime}-(\mathrm{q}-\mathrm{p})^{\prime}\left\{\mathrm{e}_{\mathrm{qG}}+\chi_{\mathrm{I}} \pi^{\prime}\right\}\right] \mathrm{dG}=\left[\mathrm{e}_{\mathrm{q}}{ }^{\prime}+(\mathrm{q}-\mathrm{p})^{\prime}\left\{\mathrm{e}_{\mathrm{qq}}-\chi_{\mathrm{I}} \mathrm{e}_{\mathrm{q}}\right\}\right] \mathrm{dq}
$$

As in the previous case, we define a policy reform such that $\mathrm{dq}=\delta . \mathrm{d} \phi$ and use the government budget constraint to solve for the change in tax rates needed to maintain government budget balance. This yields an estimate of the uniform change in affected tax rates needed to maintain equilibrium:

$$
\mathrm{d} \phi=1 /\left[\mathrm{e}_{\mathrm{q}}^{\prime} \delta+(\mathrm{q}-\mathrm{p})^{\prime}\left(\mathrm{e}_{\mathrm{qq}}-\chi_{\mathrm{I}} \mathrm{e}_{\mathrm{q}}^{\prime}\right) \delta\right] \cdot\left[\mathrm{c}_{\mathrm{G}}{ }^{\prime}-(\mathrm{q}-\mathrm{p})^{\prime}\left(\mathrm{e}_{\mathrm{qG}}+\chi_{\mathrm{I}} \pi^{\prime}\right)\right] \mathrm{dG}
$$

Replacing dp in (4) with $\delta \mathrm{d} \phi$ yields a money-metric expression paralleling (7) for the welfare impact of dG:

$$
\mathrm{e}_{\mathrm{u}} \mathrm{du}=\left[\pi^{\prime}-\mathrm{MMCF} \cdot\left\{\mathrm{c}_{\mathrm{G}}{ }^{\prime}-(\mathrm{q}-\mathrm{p})^{\prime}\left(\mathrm{e}_{\mathrm{qG}}+\chi_{\mathrm{l}} \pi^{\prime}\right)\right\}\right] \mathrm{dG}
$$

\footnotetext{
${ }^{15}$ Hatta (1977) and Anderson and Neary (1992) discuss more formal conditions. Normality is sufficient for a positive FM, while a positive FM is necessary for a plausible stability condition to be met.
} 
where $\mathrm{MMCF}=\mathrm{e}_{\mathrm{q}}{ }^{\prime} \delta /\left[\mathrm{e}_{\mathrm{q}}{ }^{\prime} \delta+(\mathrm{q}-\mathrm{p})^{\prime}\left(\mathrm{e}_{\mathrm{qq}^{-}} \chi_{\mathrm{I}_{\mathrm{q}}}{ }^{\prime}\right) \delta\right]$ is an uncompensated measure of the marginal cost of funds. For a single tax on labor, this is exactly the uncompensated MCF proposed by Mayshar (1991, p1329) and used by Ballard and Fullerton (1992). Many estimates of these uncompensated measures are available in the literature (see Dahlby 2008, p137)

Equations (7) and (11) provide equivalent characterizations of optimal policies. In either case the value of the change in the vector of public goods provide is equal to the marginal social cost of their provision defined either in terms of compensated or uncompensated marginal responses.

$$
\pi^{\prime} \mathrm{dG}=\operatorname{MCF}\left\{\mathrm{c}_{\mathrm{G}^{\prime}}{ }^{\prime}(\mathrm{q}-\mathrm{p})^{\prime} \mathrm{e}_{\mathrm{qG}}\right\} \mathrm{dG}=\operatorname{MMCF} \cdot\left\{\mathrm{c}_{\mathrm{G}}{ }^{\prime}-(\mathrm{q}-\mathrm{p})^{\prime}\left(\mathrm{e}_{\mathrm{qG}}+\chi_{\mathrm{l}} \pi^{\prime}\right)\right\} \mathrm{dG}
$$

Equation (11) can be re-expressed in an equivalent form that avoids the awkward feature that the marginal cost of public goods includes the virtual price of those goods. If the marginal cost is defined as $c_{G}{ }^{\prime}-(q-p)^{\prime} e_{q G}$ the marginal benefit of public goods in the uncompensated approach includes an income effect in:

$$
\mathrm{e}_{\mathrm{u}} \mathrm{du}=\left[\left(1-\operatorname{MMCF} \cdot(\mathrm{q}-\mathrm{p}) \cdot \chi_{\mathrm{I}}\right) \pi^{\prime}-\mathrm{MMCF} \cdot\left\{\mathrm{c}_{\mathrm{G}}{ }^{\prime}-(\mathrm{q}-\mathrm{p})^{\prime} \mathrm{e}_{\mathrm{qG}}\right\}\right] \mathrm{dG} .
$$

The simple intuition behind this formulation is as follows: if the marginal cost of taxation is reduced because adverse income effects increase the supply of taxed effort, the benefits of public goods must be correspondingly reduced because the favorable income effects they generate will reduce the supply of effort. This formulation is also useful because it shows the size of the required adjustment to the value of public goods, $\pi$, required to obtain a money-metric marginal benefit of public good provision is (1 - MMCF.(q - p). $\left.\chi_{\mathrm{I}}\right)$. This benefit multiplier depends on income effects on all tax rates but is, like FM, invariant to the public goods provided or the tax changes used to finance 
them. It is, in fact, the inverse of the FM, except that it uses MMCF rather than MCF in its calculation.

Accurate evaluation of this benefit multiplier - which has not, to our knowledge, previously appeared in the literature-requires knowledge of all of the relevant marginal tax rates on individuals, but a rough evaluation of its order of magnitude can be obtained. If we use the MMCF of 1.07 suggested by Fullerton (1991), a marginal tax rate of 0.4 for all taxes on income and consumption, and an income elasticity of 0.4 as suggested by Feldstein (1999), we would need to reduce the estimated benefits of public goods by 17 percent when using the MMCF instead of the MCF. With the MMCF of 2.0 suggested by Feldstein, the reduction would be 32 percent.

It helps in comparing the compensated with the uncompensated approach to collect key expressions in a table. Paralleling the treatment of tax changes as a scalar multiple of some reform direction, assume that government supply of goods is given by $d G=\gamma d g$ where $\gamma$ is a vector directing the scalar change in government supply dg. The table below sets out the elements of the compensated and uncompensated approaches to evaluating $e_{u} d u / d g$, the marginal welfare payoff from the expansion of government, paid for by the specified tax change. 


\begin{tabular}{|c|c|c|}
\hline & Compensated approach & Uncompensated approach \\
\hline $\begin{array}{c}\text { Marginal Cost of } \\
\text { Funds }\end{array}$ & $M C F \equiv \frac{e_{q}^{\prime} \delta}{e_{q}^{\prime} \delta+(q-p)^{\prime} e_{q q} \delta}$ & $M M C F \equiv \frac{e_{q}^{\prime} \delta}{e_{q}^{\prime} \delta+(q-p)^{\prime}\left(e_{q q} \delta-\chi_{I} e_{q}^{\prime} \delta\right)}$ \\
\hline Fiscal Multiplier & $F M \equiv \frac{1}{1-M C F(q-p)^{\prime} \chi_{I}}$ & --- \\
\hline $\begin{array}{c}\text { Marginal } \\
\text { Welfare Payoff }\end{array}$ & $\begin{array}{l}F M \cdot \pi^{\prime} \gamma \\
-F M \cdot M C F\left\{c_{G}{ }^{\prime}-(q-p)^{\prime} e_{q G}\right\} \gamma\end{array}$ & $\begin{array}{l}{\left[1-M M C F(q-p)^{\prime} \chi_{I}\right] \pi^{\prime} \gamma} \\
-M M C F\left\{c_{G}{ }^{\prime}-(q-p)^{\prime} e_{q G}\right\} \gamma\end{array}$ \\
\hline
\end{tabular}

The marginal welfare payoffs of the bottom row are equal by construction in a consistent model. But the equivalence must be carefully constructed. The virtual valuation term $\pi^{\prime} \gamma$ is multiplied by FM in the compensated approach and by $1-M M C F(q-p)^{\prime} \chi_{I}$ in the uncompensated approach. In the second line of the bottom row the full fiscal cost of the government provision $\left\{c_{G}{ }^{\prime}-(q-p)^{\prime} e_{q G}\right\} \gamma$ is alternately multiplied by $F M \cdot M C F$ in the compensated approach and MMCF in the uncompensated approach. Notice that no simple equivalence of the two approaches can be established in the presence of income effects: dividing through the terms in the bottom row of the table by $F M$ yields a compensation measure in the middle column equal to $\pi^{\prime} \gamma-M C F\left\{c_{G}{ }^{\prime}-(q-p)^{\prime} e_{q G}\right\} \gamma$ while on the right the resulting coefficients attached to $\pi^{\prime} \gamma$ and $\left\{c_{G}{ }^{\prime}-(q-p)^{\prime} e_{q G}\right\} \gamma$ are not equal to one. If the uncompensated MMCF measure is to be used, uncompensated measures must be used throughout the evaluation to achieve consistency. If the inclusion of income effects on taxed goods in the denominator of the MMCF, through the term $\chi_{\mathrm{I}} \mathrm{e}_{\mathrm{q}}{ }^{\prime} \delta$, reduces the measured cost of taxation - as in the important case of taxes that bear on labor when leisure is a normal 
good - this benefit is offset by the addition of the term $\operatorname{MMCF}(\mathrm{q}-\mathrm{p}) \chi_{1} \pi^{\prime} \mathrm{dG}$, which takes into account the income effects on taxed goods of providing public goods.

The overall income effect of raising taxes and using them to pay for a marginal unit of public goods is zero at the point where the uncompensated marginal benefits of public goods equal their uncompensated marginal social costs. This is why the use of the uncompensated measures has no policy significance. Despite what is frequently suggested (see Ballard and Fullerton 1992, p119), this lack of policy significance applies whether or not the public good is a perfect or an imperfect substitute for cash. Income effects from public good provision need to be considered when using an uncompensated approach in all cases where the public good affects welfare.

Unfortunately, many studies advocating the use of the MMCF approach have not noted the consequent need to adjust the measured benefits of public goods for the income effects of public good provision on tax revenues - creating an impression of policy significance. Even where the needed adjustment of the estimated benefits of public provision of goods has been highlighted, as in Browning, Gronberg and Liu (2000), the nature of the adjustment required in applied work has not previously been pointed out. While it is true that the benefit estimates under the compensated and money-metric approaches differ in their choice of numeraire, knowing this alone seems much less helpful to those undertaking applied studies than a specific adjustment formula such as those presented in equation (11) or (11').

Our preference is to use the compensated MCF measure where possible. A key advantage of a compensated measure is the ability to make comparisons across countries. The compensated measure is a measure of the actual transfer from outside the system to 
the private sector that would have the same effect on welfare as the combination of the change in public good provision and in the taxes needed to finance their provision. When evaluating, for example, the benefits of a trade agreement or an internationally coordinated tax reform, use of the compensated approach allows comparison and addition of the benefits accruing to all countries or regions and calculation of any compensationor side-payments - that might be needed to maintain utility levels, or might be used to maintain production efficiency (Keen and Wildasin 2008). For all countries, these amounts of international compensation can be calculated using a common standard of the size of the transfer from abroad required by each country. By contrast, when a money metric measure is used, it is not possible to make comparisons across countries without dividing each country's measured benefit by its own FM.

An additional advantage of the compensated measure is greater ease of decentralizing public decision making when government-provided goods are diverse in their type and economic impacts. An agency responsible for providing a particular good must assess $\pi$ and (q-p) $\mathrm{e}_{\mathrm{qG}}$ for the particular good it is providing. Clearly, information on $\pi$ is essential to informed decision making. Once the question is formulated in this way, it is likely that the agency will be able to make a reasonably informed decision about $\mathrm{e}_{\mathrm{qG}}$. When, for instance, the public good is a perfect substitute for a private good, $\mathrm{e}_{\mathrm{qG}}$ will be the scalar -1 . The additional adjustment to the cost or benefit of public goods required under the uncompensated approach, $\operatorname{MMCF}(q-p) \chi_{I}$ per unit of direct benefit $\left(\pi^{\prime} d G\right)$, is, by contrast, always the same for a dollar's worth of income from any set of public goods. If the money metric approach is to be used, a common value for this coefficient, should be used by all agencies responsible for evaluating individual projects. To our knowledge, 
such an adjustment has never been identified in the literature, much less adopted in practice, when using MMCF measures.

As we have shown, only one type of measure is needed for analysis of public good provision, and standardizing on the compensated measure would reduce the counter-productive proliferation of alternative welfare measures that has been the source of much confusion. If, however, only an uncompensated measure is available, then equation (11) makes clear that it can be used to evaluate provision of public goods as long as the income effects resulting from the provision of public goods are taken into account in assessing the measured benefit of the good. This is important as most of the available studies of the marginal cost of funds for particular taxes provide results either in money metric or in compensated form.

The one case typically identified as allowing use of the MMCF to compare the benefits of public goods and their cost is the situation considered by Ballard and Fullerton (1992, p124), where public goods and taxed private goods are "ordinary independents". In this case, substitution effects on tax revenues $\left(\mathrm{e}_{\mathrm{qG}}\right)$ exactly offset the income effects from provision of the public goods $\left(\chi_{1} \pi^{\prime}\right)$ for all taxed goods, so that $\left(\mathrm{e}_{\mathrm{qG}}+\chi_{\mathrm{I}} \pi^{\prime}\right) \mathrm{dG}=0^{16}$ and a special case of equation (11) applies:

$$
\mathrm{e}_{\mathrm{u}} \mathrm{du}=\left[\pi^{\prime}-\mathrm{MMCF} \cdot \mathrm{c}_{\mathrm{G}}{ }^{\prime}\right] \mathrm{dG}
$$

However, this situation relies, at best, on pure coincidence, as emphasized by Wildasin (1979; 1984). Further, it is infeasible in cases where income and substitution effects operate in the same direction, such as when an increase in public good provision reduces

\footnotetext{
${ }^{16}$ This condition for taxed goods is sufficient, rather than necessary. A weaker condition, that ( $q$ $\mathrm{p})^{\prime}\left(\mathrm{e}_{\mathrm{qG}}+\chi_{\mathrm{I}} \pi^{\prime}\right)=0$, would allow use of MMCF without requiring that there be zero impacts on consumption of individual taxed goods.
} 
the volume of taxed goods through substitution effects (as when public goods are complements to leisure, like roads to the beach) and the real income gains due to the public good provision also reduce the volume of taxed goods (as with a tax on labor supply).

Much attention has been focused on the very special cases in which the public good and the taxed private goods are ordinary independents, or are compensated independents (see, for example, Wildasin 1984). As we have shown, the MMCF can be used in the first case, and the MCF in the second. However, it seems desirable to specify a more general specification which allows for any income and substitution effects that may exist, and to choose either the MCF or the MMCF, and then to deal with any required adjustments associated with spending or revenue effects.

Many studies try to assume away substitution and income effects of public good provision by invoking separability between the public good and taxed private goods. However, assuming separability (as in Ballard and Fullerton 1992, p126 and many other studies) is not sufficient to ensure that changes in public good provision have no impact on consumption of taxed goods. While separability places restrictions on compensated substitution effects, it need not eliminate them (Deaton and Muellbauer, 1980, p128). No matter how strong the assumptions imposed on net substitution parameters, the need to include the income effects of public good provision on the demand for taxed goods highlighted by the $\chi_{1} \pi^{\prime}$ term in equation (11) means that the impacts of public good provision on the volume of goods subject to tax cannot be ignored under the uncompensated approach. 
Examination of equations (6), (7) and (11) also raises questions about the widelyaccepted assignment (see Ballard 1990; Dahlby 2008) of compensated measures of the marginal cost of funds to the case of differential tax changes with constant revenue, and uncompensated measures to the cost of public funds raised for the provision of public goods. Equations (6) and (11) show clearly that either the compensated or the uncompensated MCF can be used to measure the cost of raising public funds for the provision of public goods.

The comparison of (6) with (7) and (11) makes clear that the real distinction between measures for the impact of public good provision on welfare is the choice of measurement approach, rather than of "thought experiment". Equation (6) measures the welfare impact of public good provision in terms of the compensation to the private sector from outside the economy needed to leave the private sector indifferent to a marginal change in provision of public goods. Equations (7) and (11) measure the impact in terms of the domestic private sector's money-metric valuation of the change. Alternative measures, more in the spirit of Little and Mirrlees (1974), that use income in the hands of government as the numeraire, as in Jones (2005), could be obtained by dividing (7), (11) or equation (14) in the Appendix throughout by FM.MCF. As might be expected, the choice of numeraire is irrelevant to the policy conclusion.

\section{Conclusions}

In this paper, we provide a framework to guide decisions on the benefits of government provision of goods and services. The model we provide is simple but general, incorporating the benefits of public goods to households and producers; a very 
general multiple-output, multiple-input characterization of public good provision; and taking full account of the government's financing options through packages of tax changes.Our model provides a potential template for applied work that would draw on estimates of the marginal contribution of provision of government goods from the impact evaluation literature, and take account of the likely declining marginal productivity from increased provision of government goods.

Our analysis enables us to provide a simple rule for evaluating government provision of public goods which reinstates the Pigou-Harberger-Browning conclusion that the costs of providing public goods must take into account the compensated marginal costs of raising government revenues, unless one is willing to adjust the measured costs of public good provision (or their measured benefits) for the income-effect-determined changes in tax revenues resulting from provision of public goods.

If the income effects associated with tax-induced changes in prices and the income effects associated with provision of public goods are taken into account, considerable simplification is possible, with the tax-revenue effects associated with both sets of income changes being collected together in a multiplier term sometimes termed a Hatta (1977) coefficient. Another important simplification arises from reorganizing the impacts of government provision into a fiscal cost that may be project-specific - this allows us to cut Snow and Warren's (1996) Gordian Knot that requires estimation of the impacts of government spending on private sector behavior before progress can be made on measuring MCFs.

We show that either the compensated or the uncompensated measures can be used for policy guidance, as long as the approach is followed consistently, and all relevant 
income terms are included. This allows us to reject the widely-followed rule that an uncompensated MCF should be used for decisions about public good provision and a compensated MCF only for differential-incidence comparisons of different taxes. If uncompensated measures of the MCF are used, we provide a standard adjustment for the benefits or costs of public goods that must be applied before comparing the benefits of the public good with its fiscal costs.

Given a choice of approaches, we prefer the compensated measures on the grounds that they provide measures of potential compensating international transfers, and that they embody the useful benchmark of an MCF of unity for a lump-sum tax, even when there are other income-responsive taxes in the initial tax base. Since there is a clear consensus (see Ballard 1990) that the compensated measure can be used for differentialincidence problems in which taxes are changed while holding government revenues constant, the compensated MCF can be used for both differential-incidence and balancedbudget analysis.

Once the income effects associated with provision of public goods have been taken into account, the use of the uncompensated marginal cost of funds has none of the profound policy implications attributed to it by Ballard and Fullerton (1992, p122) and many other authors. At least in the well-researched case of US taxes that bear on labor, and by extension to taxes that bear on labor in other countries, the resulting exclusion of these income effects seems to imply a considerable increase in the measured cost of raising tax revenues relative to estimates based on the current consensus approach using the uncompensated MCF without an adjustment for the income effects of public good provision. 


\section{Appendix: Interpreting the FM and the MCF}

To interpret the FM and the MCF, we begin by differentiating the government and private sector budget constraints with respect to $\alpha, \beta$, q and $\mathrm{u}$, with $\mathrm{G}$ and $\mathrm{p}$ held constant. In this situation, the counterparts of equations (3) and (4) are:

$$
\begin{aligned}
& e_{q}^{\prime} d q-(q-p){ }^{\prime} e_{q q} d q-(q-p) e_{q u} d u=d \beta \\
& \mathrm{e}_{\mathrm{q}}{ }^{\prime} \mathrm{dq}+\mathrm{e}_{\mathrm{u}} \mathrm{du}=\mathrm{d} \alpha
\end{aligned}
$$

To interpret the FM, we consider the case of an exogenous $d \alpha$ where dq and du are endogenously determined, and $\mathrm{d} \beta=0$. As in Section II, we let $\mathrm{dq}=\delta \mathrm{d} \phi$ and solve $\left(3^{\prime}\right)$ for the scalar $\mathrm{d} \phi$ yielding:

$$
\mathrm{d} \phi=-1 /\left[\mathrm{e}_{\mathrm{q}}{ }^{\prime} \delta+(\mathrm{q}-\mathrm{p})^{\prime} \mathrm{e}_{\mathrm{qq}} \delta\right] .(\mathrm{q}-\mathrm{p}) \mathrm{e}_{\mathrm{qu}} \mathrm{du}
$$

Substituting the resulting expression for $\mathrm{dp}$ into $\left(4^{\prime}\right)$ and rearranging yields:

$$
\begin{aligned}
& -e_{\mathrm{q}} \delta /\left[\mathrm{e}_{\mathrm{q}} \delta+\left(\mathrm{q}-\mathrm{p}^{*}\right)^{\prime} \mathrm{e}_{\mathrm{qq}} \delta\right] \cdot(\mathrm{q}-\mathrm{p})\left(\mathrm{e}_{\mathrm{qu}} / \mathrm{e}_{\mathrm{u}}\right) \mathrm{e}_{\mathrm{u}} \mathrm{du}+\mathrm{e}_{\mathrm{u}} \mathrm{du}=\mathrm{d} \alpha \\
& \text { or } \quad\left(1-\operatorname{MCF}(\mathrm{q}-\mathrm{p}) \chi_{\mathrm{I}}\right) \cdot \mathrm{e}_{\mathrm{u}} \mathrm{du}=\mathrm{d} \alpha \\
& \text { or } \quad \mathrm{e}_{\mathrm{u}} \mathrm{du}=\left[1 /\left(1-\operatorname{MCF}(\mathrm{q}-\mathrm{p}) \chi_{\mathrm{I}}\right)\right] \cdot \mathrm{d} \alpha=\mathrm{FM} \cdot \mathrm{d} \alpha
\end{aligned}
$$

which shows that FM is the value placed by the private sector on a one-unit transfer from the rest of the world to the private sector.

To interpret the MCF, we begin with equations $\left(4^{\prime}\right)$ and $\left(5^{\prime}\right)$ and consider the case of an exogenous $d \beta$ where $d q$ and $d \alpha$ are endogenously determined, and $d u=0$. As in Section II, we assume the government balances its budget by changing taxes in a particular way and use $\mathrm{dq}=\delta \mathrm{d} \phi$ to solve $\left(3^{\prime}\right)$ for the scalar $\mathrm{d} \varphi$ yielding:

$$
\mathrm{d} \phi=-1 /\left[\mathrm{e}_{\mathrm{q}}{ }^{\prime} \delta+\left(\mathrm{q}-\mathrm{p}^{*}\right)^{\prime} \mathrm{e}_{\mathrm{qq}} \delta\right] . \mathrm{d} \beta
$$


Substituting the resulting value of dq into $\left(4^{\prime}\right)$ with $d u=0$ yields the expression for the change in the transfer to the private sector required to maintain utility given the change in the government's transfer to the rest of the world:

$$
\mathrm{d} \alpha=-\mathrm{e}_{\mathrm{q}} \delta /\left[\mathrm{e}_{\mathrm{q}}{ }_{\mathrm{q}} \delta+(\mathrm{q}-\mathrm{p})^{\prime} \mathrm{e}_{\mathrm{qq}} \delta\right] \cdot \mathrm{d} \beta=- \text { MCF.d } \beta
$$

This shows that the MCF can be interpreted as the compensation from the rest of the world to the private sector needed to compensate for using a tax to transfer a dollar from the private sector to the government.

\section{To interpret the money metric value of a transfer to the government}

If we assume that the government receives an increased transfer from the rest of the world, $\mathrm{d} \beta$, and that it refunds this to the household by a reduction in taxes, and that the household responds to the consequent increase in income by adjusting its spending on taxed goods, we can use equations (12) and (13) to assess the consequent money-metric change in welfare:

$$
\mathrm{e}_{\mathrm{u}} \mathrm{du}=\text { FM.MCF.d } \beta
$$

The MCF term adjusts the transfer from its value in the hands of government to its value as a transfer to the private sector, allowing for the benefits associated with the government's ability to lower its tax rates. The FM term adjusts the value from that of a transfer to the private sector to its money metric valuation, allowing for the income effects on volumes of taxed goods. 


\section{References}

Anderson, J. E. and Martin, W. 1996. The welfare analysis of fiscal policy: a simple unified account, Working Paper No. 316, Department of Economics, Boston College.

Anderson, J.E. and Neary, J.P. 1992. Trade reform with quotas, partial rent retention, and tariffs. Econometrica 60(1), 57-76.

Atkinson, A. and Stern, N. 1974. Pigou, taxation and public goods. Review of Economic Studies 41, 119-128.

Auerbach, A. 1985. The theory of excess burden and optimal taxation. in Auerbach, A. and Feldstein, M. eds. Handbook of Public Economics, Vol 1. North Holland, Amsterdam.

Auriol, E. and Warlters, 2006. The marginal cost of public funds in developing countries: an application to 38 African countries. CEPR Discussion Paper 6007, Centre for Economic Policy Research, London.

Ballard, C. 1990. Marginal welfare cost calculations: differential analysis versus balanced-budget analysis. Journal of Public Economics 41, 263-76.

Ballard, C. and Fullerton, D. 1992. Distortionary taxes and the provision of public goods. Journal of Economic Perspectives 6(3), 117-31.

Bourguignon, F., Diaz-Bonilla, C. and Lofgren, H. 2008. Aid, Service Delivery and the MDGs in an Economy-Wide Framework. Policy Research Working Paper 4683, World Bank.

Browning, E. 1976. The marginal cost of public funds. Journal of Political Economy 84, 283-98.

Browning, E. 1987. On the marginal welfare cost of taxation. American Economic Review 77(1), 11-23.

Browning, E., Gronberg, T. and Liu, Liqun 2000. Alternative measures of the marginal cost of funds. Economic Inquiry 38(4):591-9.

Christiansen, V. 2007. Two approaches to determine public good provision under distortionary taxation. National Tax Journal LX(1): 25-43.

Creedy, J. 2000. Measuring welfare changes and the excess burden of taxation. Bulletin of Economic Research 52(1), 1-47. 
Dahlby, B. 1998. Progressive taxation and the social marginal cost of public funds. Journal of Public Economics 67, 105-122.

Dahlby, B. 2008. The Marginal Cost of Public Funds: Theory and Applications, MIT Press, Cambridge, MA.

Deardorff, A. 1990. On the likelihood of factor price equalization with nontraded goods. International Economic Review 31(3):589-96.

Deaton, A. and Muellbauer, J. 1980. Economics and Consumer Behavior. Cambridge University Press, Cambridge.

Devarajan, S., Squire, L. and Suthiwart-Narueput, S. 1997. Beyond rate of return: reorienting project appraisal. World Bank Research Observer 12, 35-46.

Diamond, P. and Mirrlees, J. 1971. Optimal taxation and public production. American Economic Review 61, 8-27 and 261-78, March and June.

Drèze, J. and Stern, N. 1987. The theory of cost-benefit analysis. in Auerbach, A. and Feldstein, M., eds., Handbook of Public Economics, Vol II. Elsevier North Holland, Amsterdam.

Feldstein, M. 1995. The effect of marginal tax rates on taxable income: a panel study of the 1986 tax reform act. Journal of Political Economy 103(3), 551-72, June.

Feldstein, M. 1999. 'Tax avoidance and the deadweight loss of the income tax. Review of Economics and Statistics 81(4), 674-80.

Fullerton, D. 1991. Reconciling recent estimates of the marginal welfare cost of taxation. American Economic Review 81(1), 302-8.

Gruber, J. and Saez, E. 2002. The elasticity of taxable income: evidence and implications. Journal of Public Economics 84, 1-32.

Hatta, T. 1977. A theory of piecemeal policy recommendations. Review of Economic Studies 44(1), 1-21, February.

Jones, C. 2005. Applied Welfare Economics, Oxford University Press, London.

Kaplow, L. 1996. The optimal size of public spending and the distortionary cost of taxation. National Tax Journal 49(4), 513-33. December.

Kaplow, L. 2004. On the (Ir)Relevance of distribution and labor supply distortion to government policy. Journal of Economic Perspectives 18(4), 159-75. 
Keen, M. and Wildasin, D. 2004. Pareto-Efficient International Taxation. American Economic Review 94(1):259-75.

Khandker, S., Koolwal, G. and Samad, H. 2010. Handbook on Impact Evaluation. Wordl Bank, Washington DC.

Kleven, H. and Kreiner, C. 2006. The marginal cost of public funds: hours of work versus labor force participation. Journal of Public Economics 90:1955-73.

Komiya, R. 1967. Non-traded goods and the pure theory of international trade. International Economic Review 8(2):132-52.

Little, I. and Mirrlees, J. 1974. Project Appraisal and Planning for Developing Countries. Heinemann, London.

Liu, Liqun 2004. The marginal cost of funds and the shadow prices of public sector inputs and outputs. International Tax and Public Finance 11, 17-29.

Mayshar, J. 1990. On measures of excess burden and their interpretation. Journal of Public Economics 43, 263-89.

Mayshar, J. 1991. On measuring the marginal cost of funds analytically. American Economic Review 81(5), 1329-35.

Neary, J. P. 1995. Trade liberalisation and shadow prices in the presence of tariffs and quotas. International Economic Review 36(3), 531-554, August.

Pigou, A. 1947. A Study in Public Finance. Macmillan, London.

Ravallion, M. 2008.Evaluating Anti-Poverty Programs. Handbook of Development Economics, Vol 4, Chapter 59, 3788-846.

Samuelson, P. 1954. The pure theory of public expenditure. Review of Economics and Statistics 36(4), 397-9.

Sandmo, A. 1998. Redistribution and the marginal cost of public funds. Journal of Public Economics 70, 365-82,

Schöb, R. 1994. On marginal cost and marginal benefit of public funds. Public Finance 49(1), 87-106.

Slemrod, J. and Yitzhaki, S. 2001. Integrating expenditure and tax decisions: the marginal cost of funds and the marginal benefit of projects. National Tax Journal $\operatorname{LIV}(2), 189-201$. 
Snow, A. and Warren, R. 1996. The marginal welfare cost of public funds: theory and estimates. Journal of Public Economics 61, 289-305.

Squire, L. 1989. Project evaluation in theory and practice, in Chenery, H. and T. N. Srinivasan, ,eds., Handbook of Development Economics, Volume II. Elsevier Science Publishers, Amsterdam.

Stiglitz, J. and Dasgupta, P. 1971. Differential taxation, public goods and economic efficiency. Review of Economic Studies 38, 151-74, April.

Triest, R. 1990. The relationship between the marginal cost of public funds and marginal excess burden. American Economic Review 80(3), 557-66.

Wildasin, D. 1979 Public good provision with optimal and non-optimal commodity taxation: the single consumer case. Economics Letters 4:59-64

Wildasin, D. 1984. On public good provision with distortionary taxation. Economic Inquiry XXII(2), 227-43. 